\title{
Estimating Principal Effectiveness
}

\author{
by Gregory F. Branch, Eric A. Hanushek, and Steven G. Rivkin*
}

September 2010

\begin{abstract}
Although much has been written about the importance of school leadership, there is surprisingly little quantitative evidence on the determinants or distribution of principal effectiveness. This paper uses Texas administrative data to generate semi-parametric estimates of principal value-added, describe the distribution of principal effectiveness and principal transition patterns, and examine potential channels through which principals affect school quality including the composition of teacher transitions and student absenteeism. The principal quality estimates reveal larger variation in principal quality in higher poverty schools, while the analysis of transition patterns reveals little systematic evidence of higher transition rates for more effective principals, particularly in high poverty schools. Finally, evidence of lower student absenteeism and more negative selection of exiting teachers in schools with higher value-added principals support the view that the principal fixed effects capture real quality differences.
\end{abstract}

\footnotetext{
* University of Texas at Dallas; Stanford University, National Bureau of Economic Research, and University of Texas at Dallas; Amherst College, National Bureau of Economic Research and University of Texas at Dallas, respectively. This research has been supported by the Packard Humanities Institute and the Smith Richardson Foundation, the Spencer Foundation, and the Hewlett Foundation.
} 


\title{
Estimating Principal Effectiveness
}

\author{
by Gregory F. Branch, Eric A. Hanushek, and Steven G. Rivkin
}

\section{Introduction}

School leadership is frequently described as the key element of a high-quality school, and stories of the inspirational and effective principal are plentiful and oftrepeated. ${ }^{1}$ However, it is by no means clear that market forces related to the choice of neighborhood and school provide strong incentives for principals to act in ways that foster highly effective schools. Rothstein (2006) discusses a number of possible impediments to such market forces and reports evidence consistent with absence of strong demand for effective schools. School accountability does provide an alternative and more direct incentive structure for schools and administrators that could potentially remedy information failures and strengthen market forces pushing effective schools. The potential effectiveness of accountability depends in part on the responsiveness and quality of principals. Unfortunately, little systematic evidence on the distribution of principal effectiveness exists, making it difficult to sort through alternative policy proposals.

Cullen and Mazzeo (2007) investigates the link between principal salary growth and employment transitions on the one hand and principal effectiveness as measured by state accountability rating, achievement, and productivity on the other using Texas administrative data. It finds a positive relationship between salary on the one hand and

\footnotetext{
${ }^{1}$ A large qualitative literature focuses on "effective schools" and in that generally places special emphasis on principals and leadership issues. See, for example, Edmonds (1979), Purkey and Smith (1983), or the case studies in Carter (2000).
} 
accountability rating and student achievement on the other. In addition, it finds that principals of more highly rated and higher achieving schools are more likely to persist in their current positions.

These results suggest that a higher accountability rating and higher achievement raises salary and job security, but the possible influences of confounding factors including peer composition suggest caution in interpretation of the results. Specifically, the limited set of student, school, and district controls leaves open the possibility that unobserved student or school characteristics contribute to the higher achievement or accountability rating. Consequently, the outcomes may not provide meaningful measures of actual principal effectiveness. It may also be the case that unobserved factors such as family commitment to education raise both school performance and principal pay or job persistence, but the fact that school switchers realize the largest salary increases does suggest that the accountability rating and student achievement do improve labor market outcomes.

We focus on principal value-added and take a somewhat different approach in an effort to identify the variation in principal effectiveness and factors that contribute to that variation. Specifically, we estimate principal effectiveness based on average annual value added to student mathematics test scores. ${ }^{2}$ In order to avoid complications introduced by differences in tenure, the samples are limited to observations from the first two or three years of a principal's tenure at a school. Shrinkage methods are also used to mitigate the influences of test error and other sources of measurement error.

\footnotetext{
${ }^{2}$ Brewer (1993) and Eberts and Stone (1988) also use panel data to control for student differences by adopting value-added specifications. These studies find evidence that principal quality positively affects achievement, but the possibility that unobserved student or school level characteristics introduce bias remains.
} 
We use the estimates of principal quality to describe the distribution of principal effectiveness by school poverty rate and also by principal transition status. Systematic differences by poverty rate may derive either from differences in the underlying distributions of principal quality or differences in the magnitude of the effect of principal quality on student outcomes. From case studies and anecdotal accounts, the importance of principals seems most apparent when considering schools serving disadvantaged populations. The demands of schools with poor-performing students including their more difficult working conditions and added difficulty attracting and retaining teachers may inflate the importance of having an effective leader as compared to the situation in a higher achieving school. ${ }^{3}$ Moreover, higher quality principals may be more likely to transition out of high poverty schools, and we also describe average effectiveness for stayers and movers by poverty rate to learn more about the dynamics of the principal labor market.

Following the description of the distribution of principal value added we investigate the relationship between principal quality on the one hand and teacher transitions and student attendance on the other. If estimates of principal quality actually capture differences in principal effectiveness as opposed to other confounding influences one would expect to find improvements in teacher quality and a decline in student absenteeism during the first two or three years at a school. Because high teacher turnover is associated with both improvement and decline in the quality of instruction, the level of turnover provides little information on the wisdom of principal personnel decisions. Given that principals often exert little control in the hiring process, we focus on the relationship between the quality of teachers who transition out of a school and the quality

\footnotetext{
${ }^{3}$ Hanushek and Rivkin (2007)
} 
of principals. By not rehiring less effective teachers, encouraging them to leave or retaining effective teachers, a successful principal can improve the stock of teachers over time. In contrast, a principal that alienates the more effective teachers may lower the quality of instruction.

We would also expect effective principals to improve student behavior. Discipline data are limited both in terms of the number of years and the absence of information on underlying behavior. Therefore we focus on attendance information and estimate the relationship between principal quality and absenteeism.

The next section of the paper describes the data, and Section 3 presents a description of the distribution of principals by experience, tenure, and student demographic composition. Section 4 provides a conceptual framework for the consideration of principal effectiveness. Section 5 discusses the empirical framework used to measure principal effectiveness and reports our findings on the distribution of principal quality including differences by student demographic composition. The analysis pays particular attention to problems introduced by test measurement error and differences in student characteristics among schools. This section also describes principal quality differences by transition status. As is the case for teachers, the consequence of principal turnover depends in large part on the difference in quality between the departing and entering administrators. Section 6 investigates the relationship between estimates of principal effectiveness on the one hand and the quality of departing teachers and student absenteeism on the other. Section 7 summarizes the findings and considers implications for policy. 


\section{The Texas Database}

The administrative data used in this project were constructed as part of the UTD Texas Schools Project. Working with the Texas Education Agency (TEA), this project has combined different data sources to create matched panel data sets of students and teachers. The panels include all Texas public school teachers, administrators, staff, and students in each year, permitting accurate descriptions of the schools for each principal.

The Public Education Information Management System (PEIMS), TEA’s statewide educational database, reports key demographic data including race, ethnicity, and gender for students and school personnel as well as student eligibility for a subsidized lunch. PEIMS also contains detailed annual information on teacher and administrator experience, salary, education, class size, grade, population served, and subject. Importantly, this database can be merged with information on student achievement by campus, grade, and year. Beginning in 1993, the Texas Assessment of Academic Skills (TAAS) was administered each spring to eligible students enrolled in grades three through eight. ${ }^{4}$ These criterion referenced tests, which assess student mastery of grade-specific subject matter, are merged with the student and personnel information. Reading and math tests each contain approximately 50 questions, although the number of questions and average percent correctly answered varies across time and grades. We transform all test results into standardized scores with a mean of zero and variance equal to one for each grade and year. Thus, our achievement measures describe students in terms of their relative position in the overall state performance distribution.

\footnotetext{
${ }^{4}$ Many special education and limited English proficient students are exempted from the tests. In each year roughly 15 percent of students do not take the tests, either because of an exemption or because of repeated absences on testing days.
} 
Because the years of experience in the Texas public schools variable combines both time as a teacher and as an administrator, it is not possible to measure tenure as a principal accurately for those who begin their principal career prior to 1990/91 school year, the initial year of our personnel data. Therefore, for both the descriptive analysis and the achievement modeling we concentrate on the period 1995-2001, and we allocate principals to precise experience and tenure categories in the early career while aggregating experience for six or more years.

\section{Distribution of Principals}

This section describes the distribution of principals by demographic characteristics, tenure, and student income, race, ethnicity, and achievement using data for school years 1995 to 2002. This descriptive information forms the backdrop from which to examine principal effectiveness and differences by student characteristics.

Table 1 describes trends over time in the share of all principals and first year principals who are female, black, and Hispanic respectively. Although the shares of each of these groups increase between 1995 and 2002, women show the largest percentage point gains. In 1995 roughly 53 percent of all elementary and middle school principals were women, and that increased to 62 percent by 2002 . While slightly more than half of the new principals were women in 1995, almost two thirds of the entering principals were women in 2002. The shares of black and Hispanic principals also increased by more than 10 percent during this period. Between 1995 and 2002 the black principal share increased from 9.8 to 11.2 percent, while the Hispanic principal share rose from 18 percent to 20.5 percent. It appears that growth in enrollment and the number of schools 
and principals contributed to increases in the shares of principals who are female, black and Hispanic.

Table 2 describes differences in tenure at the current school by student income, race-ethnicity, and quartile of the mathematics test score distribution. Schools are divided into quartiles on the basis of enrollment shares for each of these characteristics, and the proportions of principals with one, two, three, four, five and six or more years of tenure are reported. Note that the relatively short time frame of the sample prevents additional detail beyond six years, as even the experience variable reported in the administrative data combines years as a principal with years spent in other roles including teacher.

Although high proportion low income schools are more likely than low proportion low income schools to have first year principals and less likely to have principals who have been at the school at least six years, the division of schools by initial achievement produces much larger differences. The proportion of principals in their first year in schools with the lowest average initial achievement is roughly 40 percent higher than in schools with the highest average initial achievement, while the proportion of principals that have been at their current school at least six years is roughly 50 percent higher in the highest achievement schools. Similar differences are smaller when schools are ordered by income and far smaller when schools are ordered by black or Hispanic enrollment shares. The extent to which this captures the duel impacts of factors on achievement and principal turnover or the higher turnover of ineffective principals is not clear.

Table 3 reports principal transitions categorized by destination, new role, and tenure. Roughly 70 percent of principals remain principals in the same school for the subsequent year regardless of tenure. The probability of changing schools and remaining 
a principal rises from 5.9 percent following the first year at a school to 8.3 percent following the third though fifth years prior to falling back to 5.7 percent for those with tenures of at least six years. By comparison, the probability of transitioning to a nonprincipal role at a campus declines from 4.5 percent to 2.8 percent as tenure increases from one to at least six years. For those with at least two years of tenure approximately 2 percent transition to work as district administrators. Finally, between 1 in 5 and 1 in 6 principals exit the Texas public schools entirely regardless of tenure category. Note that limiting the sample to principals with no more than 25 years of experience in order to lessen the contribution of retirements has little impact on these patterns.

\section{Estimation of Principal Effectiveness}

Separation of the impact of principals on student achievement from the contributions of various student, school, and district characteristics is complicated by the fact that those factors contributing to achievement likely also make the school more desirable for the typical applicant for a principal position. Given the difficulty of accounting for all such factors, we use lagged test score to account for student heterogeneity and measure principal quality on the basis of average annual value-added to achievement. In preliminary specifications we also included school fixed effects in some specifications to account for unobserved, time-invariant school influences. These estimates showed a similar variance in school effectiveness as those without school fixed effects, suggesting that the demographic variables and lagged achievement capture time invariant as well as changes over time in student composition. Therefore we focus on 
specifications that do not include school fixed effects that allow cross-sectional comparisons of principal effectiveness.

The impact of a principal on school quality likely increases with tenure, and comparisons among principals should account for differences in length of service at a school. Importantly, the impact may become more positive or more negative over time, so simple linear or polynomial controls for tenure are not appropriate. On the one hand, over time a principal would be expected to learn about school operations, the effectiveness of various teachers, and other school specific factors, and such learning would presumably improve job performance. On the other hand, however, principal personnel decisions alter the stock of teachers and the school environment, and the impact of a principal increases over time as a principal accounts for more and more of the hiring and retention of the existing stock of teachers. Therefore we restrict samples to a principal's first three years (sometimes first two years) in a school and compare principals over this period.

Test measurement issues also complicate the estimation of principal quality, and we consider both measurement error and the possibility that a focus on basic skills disadvantages principals in schools with larger shares of high achieving students. Below we describe steps taken to address these concerns in the empirical analysis.

\section{A. Empirical Model}

Our basic models relate achievement (A) for student $\mathrm{i}$ in school $\mathrm{s}$ with principal $\mathrm{p}$ in year y as a function of prior achievement, observed student characteristics (X), time varying school and peer characteristics (C), and a vector of principal by school fixed effects. Adding a random error $(\varepsilon)$, the empirical model is: 


$$
A_{i s p y}=\lambda A_{i, y-1}+\beta X_{i s y}+\delta C_{s y}+\theta_{p}+\varepsilon_{i s p y}
$$

The vector $\mathrm{X}$ includes a full set of race/ethnicity indicators and indicators for subsidized lunch eligibility, special education participation, female and English as a second language classification, a switch to the earliest grade offered in a different school (including structural transitions from elementary to middle school), and a switch to other than the earliest grade offered in a new school; and the vector C includes average demographic characteristics for students in school s in year y including proportion low income, proportion classified as special needs, proportion that are recent immigrants and proportion female. All regressions also include a full set of year-by-grade indicators to account for test changes and other statewide policy changes. ${ }^{5}$

The key identifying assumption is that there are no unobserved student, community, or school factors not caused by the principal that are related to $\theta$. Given the limited demographic information available, the validity of the model hinges on the assumption that lagged achievement soaks up all confounding factors. This is a strong assumption given the difficulty of separating principal effects from other school influences not caused by the principal. Therefore we document the relationship between estimates of principal quality on the one hand and factors expected to be influenced by principals on the other in order to provide additional evidence that supports or refutes the notion that the principal fixed effects provide valid estimates of principal quality. The inclusion of school fixed effects provides an alternative method for accounting for

\footnotetext{
${ }^{5}$ Prior to running the regressions, the data are aggregated to the campus by grade-by-year level to reduce the computational burden. All tables report absolute values of t-statistics based on robust standard errors clustered by campus.
} 
confounding factors. However, these fixed effects do not capture time-varying school influences, limit the quality comparisons to principals in the same school, and given our focus on the first three years at a school we actually have only a limited number of schools with multiple principals.

\section{B. Test Measurement Issues}

Given the substantial variation in both enrollment and student demographic characteristics among schools, test error and the structure of tests potentially complicate the measurement of principal quality. Specifically, measurement error in the estimation of principal fixed effects is likely to vary inversely with enrollment, and differences in the underlying distribution of student achievement may affect the translation of principal quality into student achievement. For example, in schools where many students would score near the top at the beginning of the school year, principal quality could have very little effect on standardized test scores even if it is having substantial impact on the overall level of intellectual engagement and quality of instruction.

Measurement error in the principal fixed effect estimates clearly must be addressed. As Kane and Staiger (2002) and Jacob and Lefgren $(2005,2006)$ point out, even in the absence of confounding influences quality estimates capture both random error and true effects. Consequently variance estimates overstate the actual variation in principal effectiveness, and the magnitude of any upward bias is likely to increase as school size decreases. Following Morrison (1983) we utilize a shrinkage estimator to mitigate the impact of the test error. Normalizing average principal quality to zero, the adjusted quality estimate $\hat{\eta}_{s}^{a}$ for principal s in year y equals 


$$
\hat{\eta}_{s y}^{a}=\frac{V_{s y}}{V_{s y}+A} \hat{\eta}_{s y}
$$

where $\hat{\eta}_{s y}$ is the coefficient on the principal s dummy variable in year $\mathrm{y}, \mathrm{V}_{\mathrm{sy}}$ is the estimated variance of that estimate, and $\mathrm{A}$ is the estimated variance of the principal by spell fixed effect distribution. Essentially, the larger the fixed effect error variance for a principal spell the more the adjusted fixed effect is shrunk toward the grand mean.

A related but clearly separate issue concerns the possibility that differences in the underlying distribution of student achievement alter the translation of principal quality into student achievement. For example, principal efforts may have little effect on the TAAS scores of high achieving students who could do very well on this test focused on lower level skills even without attending school. Consequently our test score based estimates of principal quality may produce a more compressed distribution for groups of schools with higher shares of initially high achieving students. Because we are particularly interested in the possibility that principals may have larger effects in schools serving predominantly disadvantaged students who tend to have lower initial scores, this concern must be addressed in order to produce valid comparisons across schools grouped by poverty rate.

We use two alternative methods to investigate the sensitivity of the estimates to student composition. The first includes a more flexible specification of prior achievement in order to capture differences in expected test score growth by initial score. Although this likely mitigates the problem, even the inclusion of quadratic or cubic terms may not fully address the problem given the skewness of the test score distribution. Therefore our preferred method is to weight observations in all schools and years with fixed weights in 
order to produce estimates of principal quality not influenced by differences in the test score distribution among schools.

Equation 2 shows the calculation used to produce weighted school by grade by year mean test score:

$$
\bar{A}_{s g y}=\frac{1}{N_{s g y}} \sum_{i=1}^{10} \sum_{c=1}^{N_{s g y i}} \frac{F_{i}}{\text { share }_{s g y i}} A_{c s g y i}
$$

Where $F_{i}$ is the fixed weight share for decile $i$, share sgyi $_{\text {is }}$ the actual share of students in school $\mathrm{s}$ in grade $\mathrm{g}$ in year $\mathrm{y}$ in decile $\mathrm{i}, \mathrm{N}$ is enrollment, $\mathrm{A}$ is test score, and c indexes child. The weights come from the distribution of $3^{\text {rd }}$ grade mathematics achievement scores in 1994 for students in the top quartile of schools in terms of proportion of students eligible for a subsidized lunch. $F_{1}$ is the share in the bottom test score decile, $F_{2}$ in the second decile, and on up to $F_{10}$ in the top decile. The scores of students at the low end of the distribution receive disproportionate weight in schools with small shares of such students relative to the weighting sample of higher poverty schools, while the scores of such students receive less than proportional weight in schools with a high concentration of initially low achieving students.

\section{Differences in Principal Effectiveness}

This section examines the variation in principal effectiveness as measured by value-added to mathematics achievement. Following the presentation of the basic fixed effect estimates we examine the sensitivity of the observed patterns to efforts to mitigate problems introduced by inadequacies of the achievement tests. We begin by illustrating the impact of shrinking the estimates to account for test measurement error and then 
consider the effects of re-weighting to account for underlying differences in the achievement distribution among schools.

The discussion focuses on differences in the distribution of principal effectiveness by school demographic composition but also considers variation by principal transition status. Such differences receive considerable attention, and we describe the variation in effectiveness by quartile of the share of students eligible for a subsidized lunch. Because high poverty, high student turnover schools may confront more difficulties in attracting and retaining teachers and in maintaining discipline, it would not be surprising if principal quality were to have a larger effect in on outcomes in such schools. In addition, underlying differences in the distribution of principal quality may also contribute to any observed variation in principal added.

Note that what we refer to as principal value added is actually average annual school value added during the first three years of a principal's tenure. The interpretation of these semi-parametric estimates as principal effects requires strong assumptions about the success of the included variables in accounting for confounding factors and about the importance of principals in many aspects of school operations. Below we provide evidence that the pattern of these estimates conforms to other information in ways that support the belief that they capture differences in principal effectiveness. In preliminary work (not reported) we estimated principal fixed effects from specifications that also included school fixed effects. These specifications produced even larger estimates of the variance in principal quality. We choose to focus on the estimates without school fixed effects in order to provide statewide comparisons and estimate the distributions for the entire state and subgroups with greater precision. 


\section{IVa. Baseline Results}

Table 4 reports the mean, variance and $10^{\text {th }}, 25^{\text {th }}, 50^{\text {th }}, 75^{\text {th }}$, and $90^{\text {th }}$ percentiles of the principal by spell fixed effect distribution by the school poverty rate based on a sample of the first three years at a school. Going down the rows reveals monotonic relationships between the poverty rate on the one hand, and the mean and variance on the other. Specifically, the mean principal by spell fixed effect declines but the variance increases with the poverty share. An examination of the various quantiles shows that the increase in dispersion as the poverty level rises is most pronounced at the lower end of the distribution: The difference between the top and bottom poverty rate quantiles equals -0.20 standard deviations at the $10^{\text {th }}$ percentile, -0.17 standard deviations at the $25^{\text {th }}$ percentile but only 0.07 standard deviations at the $90^{\text {th }}$ percentile.

\section{IVb. Sensitivity Analysis}

The aforementioned measurement issues may not only inflate the variance estimates but may also affect the pattern of estimated principal fixed effects by school poverty share. Table 5 presents three sets of estimates that address these two issues separately and then together. The top panel contains information using the same estimates underlying the statistics reported in Table 4 but shrunk to the grand mean on the basis of the standard error estimates; the second panel reports the mean, variance, and quantiles for estimates of principal fixed effects based on reweighted data that eliminate differences in the distribution of initial achievement among principals; finally, the bottom 
panel reports results based on reweighted data that have been shrunk to remove the effects of test error.

The very close similarity between the results in the top panel and those in Table 4 and between the results in the bottom two panels of Table 5 show that shrinkage has virtually no effect on the estimated distribution of principal quality. Unlike estimates of teacher value added that often rely on fewer than 50 observations for many teachers, estimated value added for principals of even quite small schools typically come from at least several hundred test scores. Consequently the variance of the error is likely to be quite small, and it is not surprising that shrinkage has little effect on the results.

In contrast, there are marked differences among schools in the initial achievement distribution, and this raises the possibility that the greater concentration of test scores at the lower end of the achievement distribution causes the larger variance in principal quality observed for high poverty schools. Re-weighting the scores such that the estimates for all principals are based on the same underlying distribution among test score deciles mitigates this concern. However, it does potentially increase the error variance by placing greater weight on smaller cells, and this may have a particularly large effect in high poverty schools.

Both the middle and bottom panels report results based on the reweighted data, and these show a similar pattern of larger dispersion in higher poverty schools. Consistent with the notion that re-weighting increases the error variance, the use of the shrinkage estimator has a much larger effect on the re-weighted data.

IVc. Differences by Transition 
Many bemoan high rates of teacher and administrator turnover in high poverty schools, but the magnitude of the problem depends in large part on which principals are leaving. In order to gain a better understanding of this issue, we describe principal transitions following their third year in a school by principal quality and the share of students eligible for a subsidized lunch. Principals may remain in the same school as principal, remain in the same school in another capacity, take a principal position in another school, take a different position in another school, move to a central administrative position, or exit the public schools entirely. The principal quality measures are based on un-weighted data for principals with fewer than 25 years of experience in order to minimize complications introduced by the retirement decision. Note that the experience restriction has virtually no effect on the transition patterns.

Table 6 shows that with the exception of the lowest poverty schools there is not a monotonically increasing relationship between the probability of remaining in the same position and principal quality. Rather principals in the $2^{\text {nd }}$ quartile are substantially more likely to remain than those in the bottom quartile, the differential between those in the $2^{\text {nd }}$ and $3^{\text {rd }}$ quartiles tends to be somewhat smaller (or almost zero for those in the highest poverty schools), and the most effective principals are actually less likely to remain in the same position than those in the $3^{\text {rd }}$ quality quartile. In general, the probability of exiting the public schools entirely moves as the mirror image of the probability of remaining in the same position.

A troubling aspect of Table 6 is the substantial share of low performing principals who transition to principal positions at other schools. This is particularly striking in the two highest poverty categories where over $12 \%$ of poor performers make such a move. In 
contrast, less than $7 \%$ of the poorest performers in the two lower poverty categories become principals at other schools.

Another interesting aspect of Table 6 is the fact that more effective principals tend to be less likely to move into central administrative positions. This is particularly the case in higher poverty schools, where some districts may be using central administrative slots as a means to keep ineffective principals out of schools.

\section{Teacher Quality, Student Attendance and Principal Effectiveness}

We interpret the average annual value added during a principal's first three years in a school as a measure of principal effectiveness, but absent direct evidence on principal actions such an interpretation is tenuous and open to criticism. In order to provide additional evidence and understand better the channels through which principals affect achievement we now consider the relationship between principal quality on the one hand and two oft-discussed mechanisms through which principals are thought to affect school quality: the quality of the stock of teachers and student attendance. We focus on the quality of departing teachers because principals often have little information on or control over the quality of new entrants.

\section{VIa. Quality of departing teachers}

The basic idea underlying our approach is that principals successful at raising the quality of instruction will try to retain the more effective teachers and move the least effective teachers out of the school, while those who are less successful will tend to place less emphasis on teacher effectiveness in personnel decisions and be less effective in creating an environment that is attractive for better teachers. If this is the case the quality 
difference between teachers remaining in a school and those who principals ask to exit should be larger in schools with higher quality principals.

However, teachers clearly initiate many transitions out of schools, and the data do not distinguish between voluntary moves that are unrelated to the behavior of the principal and transitions influenced by principal actions. In addition, the data do not match students and teachers, meaning that we must draw inferences about teacher quality from grade average information. This avoids problems introduced by non-random assignment to classrooms that potentially biases estimates of teacher value added (See Rothstein 2009), but it prevents comparisons of the quality of stayers and leavers. Consequently, our description of the relationship between the quality of exiting teachers and principals is quite rough.

Consider an elementary school with four teachers each in grades 4 and 5 , some of whom are dismissed. With accurate measures of teacher effectiveness and information on dismissals we could investigate whether better principals are more likely to dismiss the least effective teachers. In the absence of such information, however, we focus on whether the share of exiting teachers and grade average value-added are negatively correlated within schools. This is quite a rough test of whether principals are dismissing their least effective teachers, as small grade average differences in mean value-added provide little information on the probability that there is a very low performing teacher in one grade as opposed to another. Thus there may be many circumstances in which the lowest performer teaches in the grade with the highest average teacher quality, and our approach would provide a misleading measure of whether the principal is dismissing the least effective teacher in these cases. 
Equation (2) presents the model used to investigate the relationship between the effectiveness of exiting teachers and principal quality. Here average achievement (A) in grade $\mathrm{g}$ in school $\mathrm{s}$ in year $\mathrm{y}$ is a function of prior achievement, observed student characteristics $(\mathrm{X})$, school and peer characteristics $(\mathrm{C})$, the teacher exit rate following year $y(T), T$ interacted with indicators for the $2^{\text {nd }}, 3^{\text {rd }}$, and $4^{\text {th }}$ quartiles of estimated principal quality $\left(\mathrm{Q}_{\mathrm{i}}\right)$ and a vector of campus by year fixed effects.

$$
\bar{A}_{g s y}=\lambda \bar{A}_{g s, y-1}+\beta \bar{X}_{g s y}+\delta \bar{C}_{g s y}+\gamma T_{g s y}+\sum_{i=2}^{4} \gamma_{i} T_{g s y} * Q_{i}+\eta_{s y}+\varepsilon_{g s y}
$$

Prior to reporting the regression results we describe teacher transitions to other campuses within the same district, other districts and out of the Texas public schools by principal quality and school poverty to provide a context with which to consider teacher transitions. Figure 1 shows that the teacher transition rate is highest in schools with the least effective principals regardless of the rate of school poverty, consistent with concerns that teacher turnover is quite harmful to school quality. However, in the remaining three categories there is little difference in overall turnover, with the exception of the highest poverty schools in which turnover in the $2^{\text {nd }}$ quartile of principal quality is closer to the bottom quartile than the others. In fact turnover in the top principal quality schools is uniformly higher than that in the next category.

In terms of teacher destination, it is the rate of departure to other districts that tends to be much higher in schools with the least effective principals and lower in schools with the most effective principals; in fact district switching decreases monotonically as principal quality rises in all four poverty categories. Hanushek et al (2005) finds that districts switchers tend on average to outperform teachers moving within the district and those exiting the public schools entirely, and differences in the rate of district switching is 
consistent with the notion that higher quality principals are losing a smaller share of more effective teachers.

We turn now to the results of the analysis of teacher turnover and principal quality. Table 7 reports teacher exit rate coefficients from un-weighted (top panel) and enrollment weighted (bottom panel) regressions for all schools combined (Column 1) and by school share of students eligible for subsidized lunch (Columns 2-5). The top coefficient in each panel shows the relationship between the share of exiting teachers in the grade and grade average achievement for the bottom quartile of principals, and the remaining rows show the differentials between the relationships for the other three quartiles and the bottom quartile. Negative interaction terms indicate more negative selection of exiting teachers in the other quartile than in the bottom quartile.

Both the top and bottom panels produce a similar pattern of estimates that show a monotonic pattern of increasingly negative selection for departing teachers as principal quality rises in the sample with all schools combined. In both cases the hypothesis that there is no difference by principal quality quartile in the relationship between grade average achievement and the exit rate is rejected at the 0.01 level. The fact that these estimates are based on grade averages and thus rough measures of the probability of having a very ineffective teacher may well account for the lack of significance and mitigates problems introduced by purposeful sorting of students into classrooms.

Although all interaction coefficients in Table 7 are negative, by far the strongest ordering by principal quality appears in the high poverty schools where all coefficients are negative and the coefficient for the highest quality principals is highly significant. These schools experience higher teacher turnover than lower poverty schools, which may 
result from more attracting teachers to the schools or a higher share of teachers experiencing difficulties in the classroom.

Taken as a whole, these results support the interpretation of the principal fixed effects as measures of principal quality. Not does the negative selection of exiting teachers become stronger as principal quality rises, but the strongest relationship appears in the high poverty schools, precisely the schools with the largest variance in estimated principal quality.

VIa. Student Attendance

Improvements in student behavior constitute another channel through which effective principals can improve the quality of education by reducing time lost to disruption, raising expectations, and reducing absences. Unfortunately we have only limited data on discipline and no information on expectations, but we do have information on absences. We now examine whether more effective principals increase attendance in order to investigate the existence of a connection between our measure of principal effectiveness and student absenteeism.

Table 8 reports the estimated effects of principal quality on the attendance rate from regressions of the school by year rate of attendance on average achievement in the year prior to the start of the principal's tenure and a full set of demographic characteristics; the regressions are weighted by enrollment. The results in Column 1 for all schools show that attendance is higher in schools with higher quality principals, other things equal. The strength of this relationship varies by poverty level, being weakest in the highest poverty schools in contrast to the findings for teacher turnover. This is not in line with principals having a larger effect in higher poverty schools and merits additional 
review. It should be noted that a higher rate of school switching during the academic year in higher poverty schools may introduce substantial noise into these estimates.

\section{Conclusion}

An important facet of many school policy discussions is the role of strong leadership, particularly of principals. Leadership is viewed as especially important in revitalizing failing schools. This discussion is, however, largely uninformed by systematic analysis of principals and their impact on student outcomes.

Understanding the impact of principals on learning is a particularly difficult analytical problem. The non-random sorting of principals among schools and consequent difficulty separating the contributions of principals from the influences of peers and other school factors raise questions about the degree to which principals are responsible for differential outcomes.

Panel data on student performance that are linked to principals and schools permit facilitate the identification of principal effectiveness. We use a value-added model to estimate principal fixed effects under the assumptions that lagged achievement accounts for unobserved heterogeneity and that the estimates are not confounded by unobserved school factors not caused by the principal.

The results suggest the existence of substantial variation in principal effectiveness, particularly in higher poverty and lower achieving schools. Allowance for test issues including measurement error and test difficulty does not change these results. These results are consistent with both the hypothesis that principal skill is more important 
in the most challenging schools and the hypothesis of larger variation in underlying skills in high poverty schools, and these explanations need not be mutually exclusive.

Patterns of principal transitions suggest that it is the least and most effective that tend to leave schools, suggesting some combination of push and pull factors; this pattern is particularly pronounced in higher poverty schools. A troubling finding on transitions shows that a substantial share of ineffective principals in high poverty schools take principal positions in other schools and districts.

Of course the semi-parametric estimates of principal quality raise immediate questions about interpretation and the value of supporting evidence. The finding that the negative selection of exiting teachers is stronger in schools with higher value added principals supports the view that the fixed effects capture differences in principal quality. These results also support the belief that the improvement in the stock of teacher quality provides an important channel through which principals can raise the quality of education. Finally, the findings on student attendance add further support for the semiparametric approach to the measurement of principal quality. 


\section{References}

Boyd, Don, Hamilton Lankford, Susanna Loeb, and James Wyckoff. 2005. "The draw of home: How teachers' preferences for proximity disadvantage urban schools." Journal of Policy Analysis and Management 24,no.1 (Winter):113-132.

Brewer, Dominic J. 1993. "Principals and student outcomes: Evidence from U.S. high schools." Economics of Education Review 12,no.4 (December):281-292.

Carter, Samuel Casey. 2000. No Excuses: Lessons from 21 High-Performing, HighPoverty Schools. Washington, D.C.: The heritage Foundation.

Clotfelter, Charles T., Helen F. Ladd, and Jacob L. Vigdor. 2006. "Teacher-student matching and the assessment of teacher effectiveness." Journal of Human Resources 41,no.4 (Fall):778-820.

Eberts, Randall W., and Joe A. Stone. 1988. "Student achievement in public schools: Do principals make a difference?" Economics of Education Review 7,no.3:291-299.

Edmonds, Ronald R. 1979. "Effective schools for the urban poor." Educational Leadership 37,no.1 (October):15-24.

Gates, Susan M., Jeanne S. Ringel, Lucrecia Santibañez, Cassandra Guarino, Bonnie Ghosh-Dastidar, and Abigail Brown. 2006. "Mobility and turnover among school principals." Economics of Education Review 25,no.3 (June):289-302.

Hanushek, Eric A. 1979. "Conceptual and empirical issues in the estimation of educational production functions." Journal of Human Resources 14,no.3 (Summer):351-388.

_ 1986. "The economics of schooling: Production and efficiency in public schools." Journal of Economic Literature 24,no.3 (September):1141-1177.

Hanushek, Eric A., John F. Kain, Daniel M. O'Brien, and Steve G. Rivkin. 2005. "The market for teacher quality." Working Paper No. 11154, National Bureau of Economic Research (February).

Hanushek, Eric A., John F. Kain, and Steve G. Rivkin. 2004. "Why public schools lose teachers." Journal of Human Resources 39,no.2:326-354.

Hanushek, Eric A., and Steve G. Rivkin. 2007. "Pay, working conditions, and teacher quality." Future of Children 17,no.1 (Spring):69-86.

Jacob, Brian A., and Lars Lefgren. 2005. "Principals as agents: Subjective performance measurement in education." mimeo J.F. Kennedy School of Government (June). 
. 2006. "When principals rate teachers." Education Next 6,no.2 (Spring):59-69.

Kane, Thomas J., and Douglas O. Staiger. 2002. "Volatility in school test scores:

Implications for test-based accountability systems." In Brookings Papers on Education Policy 2002, edited by Diane Ravitch. Washington, DC:

Brookings:235-269.

Purkey, Stewart C., and Marshall S. Smith. 1983. "Effective Schools: A Review." The Elementary School Journal 83,no.4 (March):427-452.

Rothstein, Jesse. 2008. "Teacher quality in educational production: Tracking, decay, and student achievement." Cambridge, MA, NBER W14442, National Bureau of Economic Research (October). 
Table 1. The Distribution of Principals by Gender, Race, Ethnicity, and Experience, 1995-2002

All Principals

$\begin{array}{ccccc} & \text { Female } & \text { Black } & \text { Hispanic } & \mathrm{N} \\ 1995 & 52.6 \% & 9.8 \% & 18.0 \% & 3,793 \\ 1996 & 54.2 \% & 10.0 \% & 18.6 \% & 3,864 \\ 1997 & 55.7 \% & 10.0 \% & 18.7 \% & 3,965 \\ 1998 & 57.6 \% & 10.3 \% & 19.2 \% & 4,026 \\ 1999 & 59.1 \% & 10.0 \% & 19.6 \% & 4,083 \\ 2000 & 59.6 \% & 10.2 \% & 20.2 \% & 4,158 \\ 2001 & 60.8 \% & 10.9 \% & 20.4 \% & 4,258 \\ 2002 & 61.5 \% & 11.2 \% & 20.5 \% & 4,331\end{array}$

First Year Principals

$\begin{array}{ccc}\text { Female } & \text { Black } & \text { Hispanic } \\ 57.5 \% & 11.3 \% & 20.8 \% \\ 62.4 \% & 14.2 \% & 21.6 \% \\ 63.8 \% & 9.6 \% & 19.8 \% \\ 63.5 \% & 13.1 \% & 23.3 \% \\ 65.0 \% & 8.6 \% & 22.6 \% \\ 61.7 \% & 14.3 \% & 20.9 \% \\ 65.0 \% & 12.9 \% & 20.9 \% \\ 65.2 \% & 13.0 \% & 23.1 \%\end{array}$


Table 2. Distribution of Principals by Tenure at Current School and Student Demographic Characteristics

Principal Tenure

proportion

$\begin{array}{lllllll}\text { quartile } & 1 & 2 & 3 & 4 & 5 & 6 \text { or more }\end{array}$

eligible for

subsidized lunch

$\begin{array}{cccccccc}\text { bottom } & 17.8 \% & 15.3 \% & 12.6 \% & 10.2 \% & 8.2 \% & 36.1 \% & 100.0 \% \\ \text { 2nd } & 19.8 \% & 15.9 \% & 12.3 \% & 9.7 \% & 7.9 \% & 34.5 \% & 100.0 \% \\ \text { 3rd } & 20.5 \% & 17.1 \% & 13.7 \% & 9.7 \% & 7.9 \% & 31.1 \% & 100.0 \% \\ \text { top } & 19.5 \% & 17.1 \% & 13.2 \% & 10.5 \% & 8.2 \% & 31.6 \% & 100.0 \%\end{array}$

proportion black

$\begin{array}{cccccccc}\text { bottom } & 20.7 \% & 17.1 \% & 13.5 \% & 10.3 \% & 7.9 \% & 30.6 \% & 100.0 \% \\ \text { 2nd } & 18.5 \% & 15.5 \% & 12.8 \% & 10.2 \% & 7.9 \% & 35.0 \% & 100.0 \% \\ \text { 3rd } & 18.3 \% & 15.9 \% & 12.6 \% & 9.7 \% & 8.6 \% & 35.0 \% & 100.0 \% \\ \text { top } & 20.1 \% & 16.8 \% & 12.8 \% & 9.9 \% & 7.8 \% & 32.7 \% & 100.0 \%\end{array}$

proportion

Hispanic

Initial Math

$\begin{array}{cccccccc}\text { bottom } & 19.1 \% & 15.7 \% & 12.2 \% & 9.9 \% & 7.9 \% & 35.2 \% & 100.0 \% \\ \text { 2nd } & 19.2 \% & 15.9 \% & 12.8 \% & 9.5 \% & 7.9 \% & 34.8 \% & 100.0 \% \\ \text { 3rd } & 19.3 \% & 16.3 \% & 12.9 \% & 10.1 \% & 8.4 \% & 33.0 \% & 100.0 \% \\ \text { top } & 19.9 \% & 17.5 \% & 13.8 \% & 10.6 \% & 8.0 \% & 30.2 \% & 100.0 \%\end{array}$

Achievement

$\begin{array}{cccccccc}\text { bottom } & 22.7 \% & 19.4 \% & 14.3 \% & 9.8 \% & 7.4 \% & 26.3 \% & 100.0 \% \\ \text { 2nd } & 20.4 \% & 16.7 \% & 12.7 \% & 10.0 \% & 8.4 \% & 31.9 \% & 100.0 \% \\ \text { 3rd } & 18.1 \% & 15.3 \% & 12.5 \% & 10.1 \% & 7.9 \% & 36.3 \% & 100.0 \% \\ \text { top } & 16.4 \% & 14.0 \% & 12.2 \% & 10.2 \% & 8.5 \% & 38.8 \% & 100.0 \%\end{array}$


Table 3. Principal Transitions by Tenure

transition

same campus

change campus, same

district

change district

same campus

change campus, same

district

change district

same district central office

new district central office

exit Texas public schools
Years of Tenure as Principal at School new role

$\begin{array}{lcccc} & 1 & 2 & 3 \text { to } 5 & 6 \text { or more } \\ \text { Principal } & 72.5 \% & 68.0 \% & 69.2 \% & 70.8 \% \\ & & & & \\ \text { Principal } & 3.9 \% & 4.9 \% & 6.0 \% & 4.7 \% \\ \text { Principal } & 2.0 \% & 2.5 \% & 2.3 \% & 1.0 \% \\ \text { Other } & 0.8 \% & 0.6 \% & 0.3 \% & 0.2 \% \\ & & & & \\ \text { Other } & 2.0 \% & 2.1 \% & 2.2 \% & 2.1 \% \\ \text { Other } & 1.7 \% & 1.7 \% & 1.1 \% & 0.5 \% \\ \text { administration } & 0.7 \% & 1.3 \% & 1.6 \% & 1.3 \% \\ \text { administration } & 0.5 \% & 0.7 \% & 0.7 \% & 0.4 \% \\ & 16.0 \% & 18.1 \% & 16.7 \% & 19.0 \% \\ & 100.0 \% & 100.0 \% & 100.0 \% & 100.0 \%\end{array}$


Table 4. Mean, Variance, and Select Quantiles of the Distribution of Principal by Spell Fixed Effects, by the Share of Students in a School That Are Eligible for Subsidized Lunch

\begin{tabular}{|c|c|c|c|c|c|c|c|}
\hline & & & \multicolumn{5}{|c|}{ Percentiles } \\
\hline & Mean & Variance & 10th & 25th & 50th & 75th & 90th \\
\hline \multicolumn{8}{|l|}{$\begin{array}{l}\text { Share low income } \\
\text { quantile }\end{array}$} \\
\hline Bottom & 0.025 & 0.025 & -0.180 & -0.063 & 0.032 & 0.134 & 0.215 \\
\hline 2nd & -0.030 & 0.031 & -0.243 & -0.142 & -0.032 & 0.086 & 0.190 \\
\hline $3 r d$ & -0.043 & 0.043 & -0.301 & -0.162 & -0.036 & 0.103 & 0.207 \\
\hline Top & -0.062 & 0.069 & -0.383 & -0.236 & -0.068 & 0.114 & 0.285 \\
\hline All & -0.028 & 0.043 & -0.286 & -0.153 & -0.019 & 0.109 & 0.222 \\
\hline
\end{tabular}


Table 5. Alternative Estimates of the Mean, Variance, and Select Quantiles of the Distribution of Principal by Spell fixed effects, by the Share of Students in a School That Are Eligible for Subsidized Lunch and Steps Taken to Mitigate Problems Related to Test Measurement

\begin{tabular}{|c|c|c|c|c|c|c|c|}
\hline & & & \multicolumn{5}{|c|}{ Percentiles } \\
\hline & Mean & Variance & 10th & 25th & 50th & 75th & 90th \\
\hline \multicolumn{8}{|l|}{ Estimates Shrunk } \\
\hline \multicolumn{8}{|l|}{$\begin{array}{l}\text { Share low income } \\
\text { quantile }\end{array}$} \\
\hline Bottom & 0.024 & 0.025 & -0.179 & -0.063 & 0.030 & 0.133 & 0.213 \\
\hline $2^{\text {nd }}$ & -0.031 & 0.030 & -0.241 & -0.141 & -0.033 & 0.084 & 0.186 \\
\hline $3^{\text {rd }}$ & -0.044 & 0.040 & -0.296 & -0.161 & -0.037 & 0.094 & 0.200 \\
\hline Top & -0.061 & 0.061 & -0.364 & -0.228 & -0.068 & 0.102 & 0.266 \\
\hline All & -0.028 & 0.040 & -0.280 & -0.150 & -0.020 & 0.106 & 0.214 \\
\hline \multicolumn{8}{|l|}{ Re-weighted Data } \\
\hline \multicolumn{8}{|l|}{$\begin{array}{l}\text { Share low income } \\
\text { quantile }\end{array}$} \\
\hline Bottom & 0.071 & 0.048 & -0.130 & -0.057 & 0.035 & 0.146 & 0.355 \\
\hline $2^{\text {nd }}$ & 0.063 & 0.052 & -0.167 & -0.070 & 0.025 & 0.154 & 0.350 \\
\hline $3^{\text {rd }}$ & 0.065 & 0.066 & -0.192 & -0.085 & 0.029 & 0.176 & 0.394 \\
\hline Top & 0.085 & 0.125 & -0.266 & -0.125 & 0.038 & 0.241 & 0.571 \\
\hline All & 0.071 & 0.073 & -0.182 & -0.082 & 0.031 & 0.174 & 0.417 \\
\hline \multicolumn{8}{|l|}{$\begin{array}{l}\text { Shrunk Estimates } \\
\text { Based on Re- } \\
\text { weighted Data }\end{array}$} \\
\hline \multicolumn{8}{|l|}{$\begin{array}{l}\text { Share low income } \\
\text { quantile }\end{array}$} \\
\hline Bottom & 0.070 & 0.042 & -0.119 & -0.050 & 0.035 & 0.143 & 0.336 \\
\hline $2^{\text {nd }}$ & 0.063 & 0.045 & -0.152 & -0.064 & 0.026 & 0.147 & 0.334 \\
\hline $3^{\text {rd }}$ & 0.064 & 0.055 & -0.170 & -0.077 & 0.030 & 0.163 & 0.368 \\
\hline Top & 0.080 & 0.091 & -0.218 & -0.102 & 0.040 & 0.216 & 0.498 \\
\hline All & 0.069 & 0.058 & -0.162 & -0.071 & 0.032 & 0.164 & 0.385 \\
\hline
\end{tabular}


Table 6. Principal Transition Distribution for Principals with less than 25 years of experience in the Texas Public Schools, by Quartile of Principal Fixed Effect and the Share of Students in a School That Are Eligible for Subsidized Lunch

\begin{tabular}{|c|c|c|c|c|}
\hline \multirow[t]{2}{*}{$\begin{array}{c}\text { Share low income quartile } \\
\text { bottom }\end{array}$} & & & & \\
\hline & \multicolumn{4}{|c|}{ Quartile of principal fixed effect } \\
\hline Fourth Year Transition & Q1 & Q2 & Q3 & Q4 \\
\hline Same campus, principal & $58.62 \%$ & $68.03 \%$ & $73.48 \%$ & $76.34 \%$ \\
\hline Same campus, other & $1.15 \%$ & $0.00 \%$ & $0.76 \%$ & $0.00 \%$ \\
\hline Moves campus, principal & $4.60 \%$ & $4.10 \%$ & $4.55 \%$ & $4.30 \%$ \\
\hline Moves campus, other & $0.00 \%$ & $0.82 \%$ & $1.52 \%$ & $2.15 \%$ \\
\hline Same district, distr. Admin & $0.00 \%$ & $4.10 \%$ & $1.52 \%$ & $2.15 \%$ \\
\hline Moves district, principal & $2.30 \%$ & $1.64 \%$ & $3.79 \%$ & $4.30 \%$ \\
\hline Move district, other & $3.45 \%$ & $0.00 \%$ & $1.52 \%$ & $0.00 \%$ \\
\hline Move district, district admin & $2.30 \%$ & $0.00 \%$ & $0.76 \%$ & $2.15 \%$ \\
\hline \multirow[t]{2}{*}{ Exits } & $27.59 \%$ & $21.31 \%$ & $12.12 \%$ & $8.60 \%$ \\
\hline & $100.00 \%$ & $100.00 \%$ & $100.00 \%$ & $100.00 \%$ \\
\hline \multicolumn{5}{|l|}{ Second } \\
\hline Fourth Year Transition & Q1 & Q2 & Q3 & Q4 \\
\hline Same campus, principal & $52.43 \%$ & $70.15 \%$ & $81.45 \%$ & $71.70 \%$ \\
\hline Same campus, other & $0.97 \%$ & $0.00 \%$ & $0.00 \%$ & $0.00 \%$ \\
\hline Moves campus, principal & $3.88 \%$ & $2.24 \%$ & $0.81 \%$ & $6.60 \%$ \\
\hline Moves campus, other & $2.91 \%$ & $0.75 \%$ & $0.81 \%$ & $0.94 \%$ \\
\hline Same district, distr. Admin & $1.94 \%$ & $0.75 \%$ & $1.61 \%$ & $0.00 \%$ \\
\hline Moves district, principal & $0.97 \%$ & $5.97 \%$ & $2.42 \%$ & $5.66 \%$ \\
\hline Move district, other & $1.94 \%$ & $3.73 \%$ & $2.42 \%$ & $0.00 \%$ \\
\hline Move district, district admin & $0.97 \%$ & $1.49 \%$ & $0.81 \%$ & $0.00 \%$ \\
\hline \multirow[t]{2}{*}{ Exits } & $33.98 \%$ & $14.93 \%$ & $9.68 \%$ & $15.09 \%$ \\
\hline & $100.00 \%$ & $100.00 \%$ & $100.00 \%$ & $100.00 \%$ \\
\hline \multicolumn{5}{|l|}{ Third } \\
\hline Fourth Year Transition & Q1 & Q2 & Q3 & Q4 \\
\hline Same campus, principal & $44.36 \%$ & $55.28 \%$ & $63.81 \%$ & $58.06 \%$ \\
\hline Same campus, other & $0.75 \%$ & $0.00 \%$ & $0.00 \%$ & $0.00 \%$ \\
\hline Moves campus, principal & $7.52 \%$ & $5.69 \%$ & $9.52 \%$ & $8.06 \%$ \\
\hline Moves campus, other & $0.75 \%$ & $2.44 \%$ & $2.86 \%$ & $1.61 \%$ \\
\hline Same district, distr. admin & $3.76 \%$ & $2.44 \%$ & $0.95 \%$ & $0.81 \%$ \\
\hline Moves district, principal & $4.51 \%$ & $4.88 \%$ & $1.90 \%$ & $7.26 \%$ \\
\hline Move district, other & $2.26 \%$ & $1.63 \%$ & $1.90 \%$ & $0.81 \%$ \\
\hline Move district, district admin & $0.75 \%$ & $2.44 \%$ & $0.00 \%$ & $0.00 \%$ \\
\hline \multirow[t]{2}{*}{ Exits } & $35.34 \%$ & $25.20 \%$ & $19.05 \%$ & $23.39 \%$ \\
\hline & $100.00 \%$ & $100.00 \%$ & $100.00 \%$ & $100.00 \%$ \\
\hline
\end{tabular}




\begin{tabular}{|c|c|c|c|c|}
\hline \multicolumn{5}{|l|}{ Top } \\
\hline & \multicolumn{4}{|c|}{ Quartile of principal fixed effect } \\
\hline Fourth Year Transition & Q1 & Q2 & Q3 & $\mathrm{Q} 4$ \\
\hline \multirow{2}{*}{$\begin{array}{l}\text { Same campus, principal } \\
\text { Same campus, other }\end{array}$} & $62.59 \%$ & $73.17 \%$ & $72.28 \%$ & $67.39 \%$ \\
\hline & $0.00 \%$ & $0.00 \%$ & $0.00 \%$ & $0.00 \%$ \\
\hline \multirow{2}{*}{$\begin{array}{l}\text { Moves campus, principal } \\
\text { Moves campus, other }\end{array}$} & $8.63 \%$ & $10.98 \%$ & $6.93 \%$ & $7.25 \%$ \\
\hline & $0.72 \%$ & $1.22 \%$ & $0.99 \%$ & $1.45 \%$ \\
\hline \multirow{6}{*}{$\begin{array}{l}\text { Same district, distr. admin } \\
\text { Moves district, principal } \\
\text { Move district, other } \\
\text { Move district, district admin } \\
\text { exits }\end{array}$} & $0.00 \%$ & $0.00 \%$ & $0.99 \%$ & $0.00 \%$ \\
\hline & $3.60 \%$ & $1.22 \%$ & $2.97 \%$ & $1.45 \%$ \\
\hline & $0.72 \%$ & $1.22 \%$ & $0.00 \%$ & $0.72 \%$ \\
\hline & $2.16 \%$ & $0.00 \%$ & $0.00 \%$ & $0.72 \%$ \\
\hline & $21.58 \%$ & $12.20 \%$ & $15.84 \%$ & $21.01 \%$ \\
\hline & $100.00 \%$ & $100.00 \%$ & $100.00 \%$ & $100.00 \%$ \\
\hline
\end{tabular}


Table 7. Coefficients on Principal Quality Quartile-Teacher Turnover Interactions from Unweighted and Weighted Regressions of Achievement on These Interactions, Lagged Achievement, Demographic Characteristics, Campus by Year Fixed Effects and Grade by Year Fixed Effects, by the Share of Students in a School That Are Eligible for Subsidized Lunch (absolute value of t-statistics in parentheses; data aggregated to campus by grade by year level)

Unweighted

\begin{tabular}{|c|c|c|c|c|c|}
\hline share teachers exiting & 0.017 & 0.023 & 0.041 & 0.017 & 0 \\
\hline & $(0.80)$ & $(0.37)$ & $(1.00)$ & $(0.45)$ & $(0.01)$ \\
\hline share exiting* 2 nd $q$ & -0.05 & -0.005 & -0.039 & -0.073 & -0.092 \\
\hline principal quality & $(1.80)$ & $(0.07)$ & $(0.78)$ & $(1.44)$ & $(1.60)$ \\
\hline share exiting*3rd q & -0.071 & -0.07 & -0.08 & -0.05 & -0.11 \\
\hline principal quality & $(2.50)$ & $(1.00)$ & $(1.47)$ & $(0.94)$ & $(1.82)$ \\
\hline share exiting* 4 th q & -0.099 & -0.049 & -0.053 & -0.079 & -0.193 \\
\hline principal quality & $(3.49)$ & $(0.70)$ & $(0.99)$ & $(1.50)$ & $(3.52)$ \\
\hline F Test-int & 4.299 & 0.829 & 0.757 & 0.937 & 4.172 \\
\hline & 0.0 & 0.478 & 0.518 & 0.422 & \\
\hline
\end{tabular}

Weighted by campus by year enrollment

$\begin{array}{lccccc}\text { share teachers exiting } & 0.008 & -0.009 & 0.063 & 0.001 & -0.016 \\ & (0.43) & (0.23) & (2.35) & (0.04) & (0.47) \\ \begin{array}{lccccc}\text { share exiting*2nd q } \\ \text { principal quality }\end{array} & -0.014 & 0.023 & -0.032 & -0.044 & -0.044 \\ & (0.59) & (0.45) & (0.82) & (0.92) & (0.80) \\ \text { share exiting*3rd q } & -0.06 & -0.037 & -0.104 & -0.046 & -0.086 \\ \text { principal quality } & (2.36) & (0.82) & (2.37) & (0.78) & (1.10) \\ & & & & & \\ \text { share exiting*4th q } & -0.072 & -0.023 & -0.057 & -0.041 & -0.194 \\ \text { principal quality } & (2.76) & (0.49) & (1.20) & (0.75) & (3.25) \\ & & & & & \\ \text { Join F Test-interactions } & 3.634 & 0.863 & 1.972 & 0.361 & 3.603 \\ \text { p-value } & 0.012 & 0.46 & 0.117 & 0.781 & 0.013\end{array}$


Table 8. Estimated Effects of Principal Quality on Student Attendance Rate Controlling for Lagged Achievement, Demographic Characteristics, and Grade Shares, by the Share of Students in a School That Are Eligible for Subsidized Lunch (absolute value of tstatistics in parentheses; data aggregated to campus by year level; estimates weighted by enrollment)

Quartiles of Poverty Share

\begin{tabular}{|c|c|c|c|c|c|}
\hline & All & Lowest & Second & Third & Highest \\
\hline Principal quality $2^{\text {nd }}$ & 0.0019 & 0.0008 & 0.0026 & 0.0044 & -0.0007 \\
\hline Quartile & $(4.42)$ & $(1.00)$ & $(3.52)$ & $(5.33)$ & $(0.81)$ \\
\hline Principal quality $3^{\text {rd }}$ & 0.0024 & 0.0024 & 0.0036 & 0.004 & -0.0013 \\
\hline Quartile & $(5.36)$ & $(3.12)$ & $(4.78)$ & $(4.33)$ & $(1.43)$ \\
\hline Principal quality top & 0.0029 & 0.0016 & 0.0049 & 0.0031 & 0.0009 \\
\hline Quartile & $(5.76)$ & $(2.04)$ & $(6.07)$ & (3.14) & $(0.91)$ \\
\hline Join F Test-interactions & 11.957 & 5.936 & 12.973 & 10.102 & 2.254 \\
\hline$p$-value & 0.000 & 0.001 & 0.000 & 0.000 & 0.081 \\
\hline
\end{tabular}


Figure 1. Teacher Transitions by Principal Effectiveness and Share of Students in a School Eligible for a Subsidized Lunch

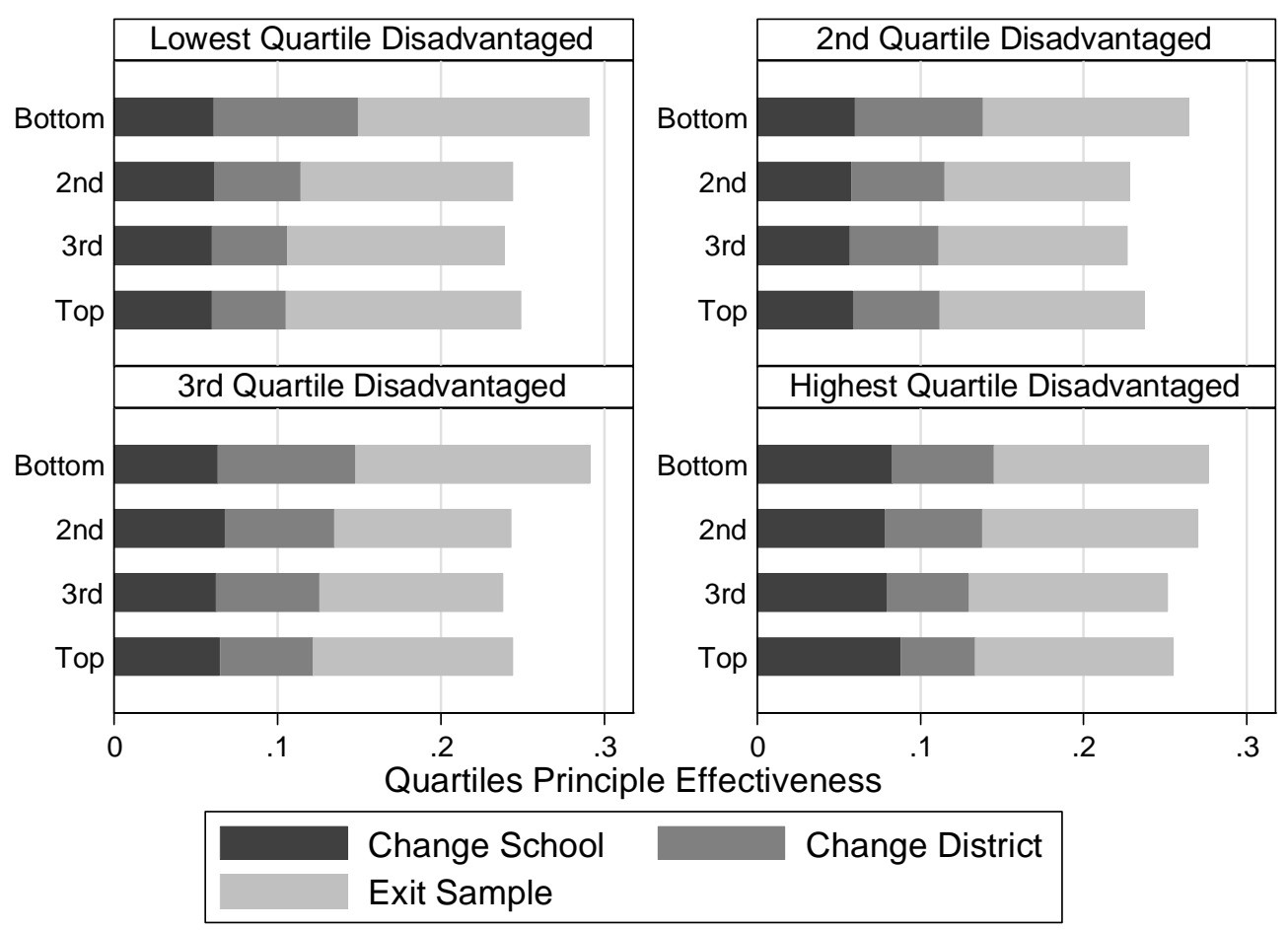

